\section{Особенности пожара на судне и способы его предотвращения}

А. Ю. Янченко

Кандидат экономических наук, доцент, yanchenko.au@corp.smtu.ru

Санкт-Петербургский государственный морской технический университет, Санкт-Петербург, Россия

А. А. Икко

Студент,

ikkonastya@gmail.com

Санкт-Петербургский государственный морской технический университет,

Санкт-Петербург, Россия

Аннотащия: В статье рассматриваются основные причины и особенности пожсара на судне. Приводится мировая статистика потерь судов по их типам и по причинам гибели. Акцентируется внимание на классификации пожаров и конструктивной защите судов. Определяются условия обеспечения пожсарной безопасности судна, а также меры предупреждения распространения возгорания и основные способы борьбы с огнем.

Ключевые слова: пожары на судах, особенности пожара на судне, классификация пожаров, противопожарные конструкции, обеспечение пожарной безопасности.

\title{
Features of a fire on a ship and ways to prevent it
}

\author{
A. Yu. Yanchenko \\ Cand. Sci. (Econ.), Assoc. Prof., \\ yanchenko.au@corp.smtu.ru \\ Saint_Petersburg State Marine Technical University, \\ Saint_Petersburg, Russia

A. A. Ikko
Student,
ikkonastya@gmail.com \\ Saint_Petersburg State Marine Technical University, \\ Saint_Petersburg, Russia
}

Abstract: The article discusses the main causes and features of a fire on a ship. The world statistics of losses of ships by their types and causes of death are given. The article is focused on the classification of fires and the constructive protection of ships. The conditions for ensuring the fire safety of the vessel as well as measures to prevent the spread of fire and the main ways of fighting fire are determined.

Keywords: fires on ships, features of a fire on a ship, classification of fires, fire-fighting structures, fire safety.

Пожар на судне относятся к наиболее опасному виду чрезвычайных ситуаций. Кроме того, пожары влекут за собой серьезные финансовые потери для судовладельцев. В 20 из 100 зарегистрированных случаев гибель судна происходит именно от пожара. Несмотря на то, что существуют определенные правила пожарной безопасности и суда оборудованы системами пожаротушения, пожары продолжают происходить, что подтверждает актуальность проблемы обеспечения пожарной безопасности на всех видах водного транспорта. 
Большинство специалистов считают, что пожары в 70\% случаев возникают по вине личного состава экипажа, и чаще всего пожары на судах происходят в порту, а не на открытом водном пространстве, и более всего подвержены пожарам грузовые суда [1].

В отчете AGCS ${ }^{1}$ «Обзор безопасности судоходства 2021» [2] представлена мировая статистика потерь по типу судов за 2011-2020 годы (см. табл. 1).

Общие потери по типу судна в 2011-2020 годах

\begin{tabular}{|l|c|c|c|c|c|c|c|c|c|c|c}
\hline & $\mathbf{2 0 1 1}$ & $\mathbf{2 0 1 2}$ & $\mathbf{2 0 1 3}$ & $\mathbf{2 0 1 4}$ & $\mathbf{2 0 1 5}$ & $\mathbf{2 0 1 6}$ & $\mathbf{2 0 1 7}$ & $\mathbf{2 0 1 8}$ & $\mathbf{2 0 1 9}$ & $\mathbf{2 0 2 0}$ & Итого \\
\hline Грузовые & 37 & 61 & 40 & 31 & 40 & 34 & 54 & 17 & 16 & 18 & $\mathbf{3 4 8}$ \\
\hline Рыболовные & 14 & 12 & 13 & 15 & 16 & 10 & 8 & 12 & 10 & 10 & $\mathbf{1 2 0}$ \\
\hline Балкеры & 14 & 11 & 15 & 5 & 13 & 5 & 7 & 2 & 2 & 2 & $\mathbf{7 6}$ \\
\hline Пассажирские & 7 & 7 & 8 & 11 & 6 & 11 & 5 & 6 & 3 & 5 & $\mathbf{6 9}$ \\
\hline Буксирные & 2 & 7 & 7 & 7 & 6 & 7 & 4 & 4 & 4 & 3 & $\mathbf{5 1}$ \\
\hline Химовозы & 4 & 8 & 10 & 2 & 3 & 7 & 4 & 1 & 0 & 1 & $\mathbf{4 0}$ \\
\hline Ролкеры & 3 & 6 & 2 & 5 & 6 & 9 & 0 & 1 & 4 & 1 & $\mathbf{3 7}$ \\
\hline Контейнеровозы & 3 & 7 & 4 & 4 & 5 & 5 & 3 & 2 & 1 & 1 & $\mathbf{3 5}$ \\
\hline Другие & 5 & 3 & 6 & 4 & 4 & 3 & 1 & 0 & 4 & 5 & $\mathbf{3 5}$ \\
\hline $\begin{array}{l}\text { Суда оффшорного } \\
\text { флота }\end{array}$ & 2 & 3 & 2 & 3 & 3 & 2 & 2 & 1 & 0 & 1 & $\mathbf{1 9}$ \\
\hline $\begin{array}{l}\text { Дноуглубительные } \\
\text { суда }\end{array}$ & 2 & 1 & 0 & 1 & 1 & 1 & 3 & 2 & 0 & 1 & $\mathbf{1 2}$ \\
\hline Танкеры & 4 & 1 & 0 & 1 & 0 & 0 & 2 & 3 & 0 & 1 & $\mathbf{1 2}$ \\
\hline Баржа & 0 & 0 & 3 & 1 & 0 & 3 & 1 & 2 & 1 & 0 & $\mathbf{1 1}$ \\
\hline Газовозы & 1 & 1 & 0 & 0 & 0 & 1 & 1 & 0 & 2 & 0 & $\mathbf{6}$ \\
\hline Неизвестные & 0 & 0 & 1 & 0 & 2 & 1 & 0 & 0 & 1 & 0 & $\mathbf{5}$ \\
\hline \multicolumn{1}{c}{ Итого } & $\mathbf{9 8}$ & $\mathbf{1 2 8}$ & $\mathbf{1 1 1}$ & $\mathbf{9 0}$ & $\mathbf{1 0 5}$ & $\mathbf{9 9}$ & $\mathbf{9 5}$ & $\mathbf{5 3}$ & $\mathbf{4 8}$ & $\mathbf{4 9}$ & $\mathbf{8 7 6}$ \\
\hline
\end{tabular}

По данным таблицы 1 можно сделать вывод, что наибольшие потери, как в общем, так и в отдельности по каждому году, несут суда грузового типа, а также рыболовные суда и балкеры, хотя наблюдается общая тенденция к снижению потерь. Не менее показательна информация, касающаяся причин, из-за которых происходят потери судов по всему миру (см. табл. 2).

Причины потери судов в 2011-2020 годах

\begin{tabular}{|l|c|c|c|c|c|c|c|c|c|c|c|}
\hline & $\mathbf{2 0 1 1}$ & $\mathbf{2 0 1 2}$ & $\mathbf{2 0 1 3}$ & $\mathbf{2 0 1 4}$ & $\mathbf{2 0 1 5}$ & $\mathbf{2 0 1 6}$ & $\mathbf{2 0 1 7}$ & $\mathbf{2 0 1 8}$ & $\mathbf{2 0 1 9}$ & $\mathbf{2 0 2 0}$ & Итого \\
\hline Затопление & 46 & 54 & 70 & 50 & 66 & 48 & 57 & 31 & 31 & 24 & $\mathbf{4 7 7}$ \\
\hline Крушение & 28 & 29 & 21 & 18 & 19 & 20 & 15 & 4 & 4 & 7 & $\mathbf{1 2 7}$ \\
\hline Пожар & 9 & 14 & 15 & 7 & 9 & 12 & 8 & 9 & 9 & 10 & $\mathbf{9 9}$ \\
\hline $\begin{array}{l}\text { Повреждение } \\
\text { техники/ отказ } \\
\text { оборудования }\end{array}$ & 6 & 15 & 1 & 5 & 2 & 10 & 9 & 0 & 0 & 1 & $\mathbf{5 1}$ \\
\hline $\begin{array}{l}\text { Повреждение } \\
\text { корпуса }\end{array}$ & 3 & 7 & 1 & 5 & 2 & 4 & 5 & 1 & 1 & 0 & $\mathbf{2 9}$ \\
\hline Столкновение & 3 & 5 & 2 & 2 & 7 & 2 & 1 & 1 & 1 & 2 & $\mathbf{2 7}$ \\
\hline $\begin{array}{l}\text { Удар о портовую } \\
\text { стену }\end{array}$ & 0 & 2 & 0 & 1 & 0 & 0 & 0 & 0 & 0 & 0 & $\mathbf{3}$ \\
\hline Пропажа & 0 & 0 & 0 & 0 & 0 & 2 & 0 & 1 & 1 & 0 & $\mathbf{3}$ \\
\hline Пиратство & 1 & 0 & 0 & 0 & 0 & 0 & 0 & 0 & 0 & 0 & $\mathbf{1}$ \\
\hline Другое & 2 & 2 & 1 & 2 & 0 & 1 & 0 & 1 & 1 & 5 & $\mathbf{1 4}$ \\
\hline \multicolumn{1}{|c|}{ Итого } & $\mathbf{9 8}$ & $\mathbf{1 2 8}$ & $\mathbf{1 1 1}$ & $\mathbf{9 0}$ & $\mathbf{1 0 5}$ & $\mathbf{9 9}$ & $\mathbf{9 5}$ & $\mathbf{5 3}$ & $\mathbf{4 8}$ & $\mathbf{4 9}$ & $\mathbf{8 7 6}$ \\
\hline
\end{tabular}

\footnotetext{
${ }_{1}$ Allianz Global Corporate \& Specialty (AGCS) - ведущий глобальный оператор корпоративного страхования и ключевое бизнес-подразделение группы Allianz.
} 
Из таблицы 2 видно, что пожары стоят на третьем месте по числу потерь, таким образом являясь одной из наиболее частых причин гибели судна и доказывая необходимость особенно внимательно подходить к вопросу обеспечения противопожарных мер.

Основным условием недопущения пожара на судне является постоянная бдительность со стороны экипажа, особенно при наличии на судне огнеопасных грузов, и строгое выполнение противопожарных правил. Особенно это касается машинных отделений, на которые приходятся $25 \%$ от всех пожаров в помещениях на судне. В первые минуты пожара в таком помещении образуется сильное задымление и поднимается высокая температура, что создает значительные трудности в ликвидации пожара.

Быстрому распространению и трудностям борьбы с пожарами способствует многообразие факторов (см. рис. 1).

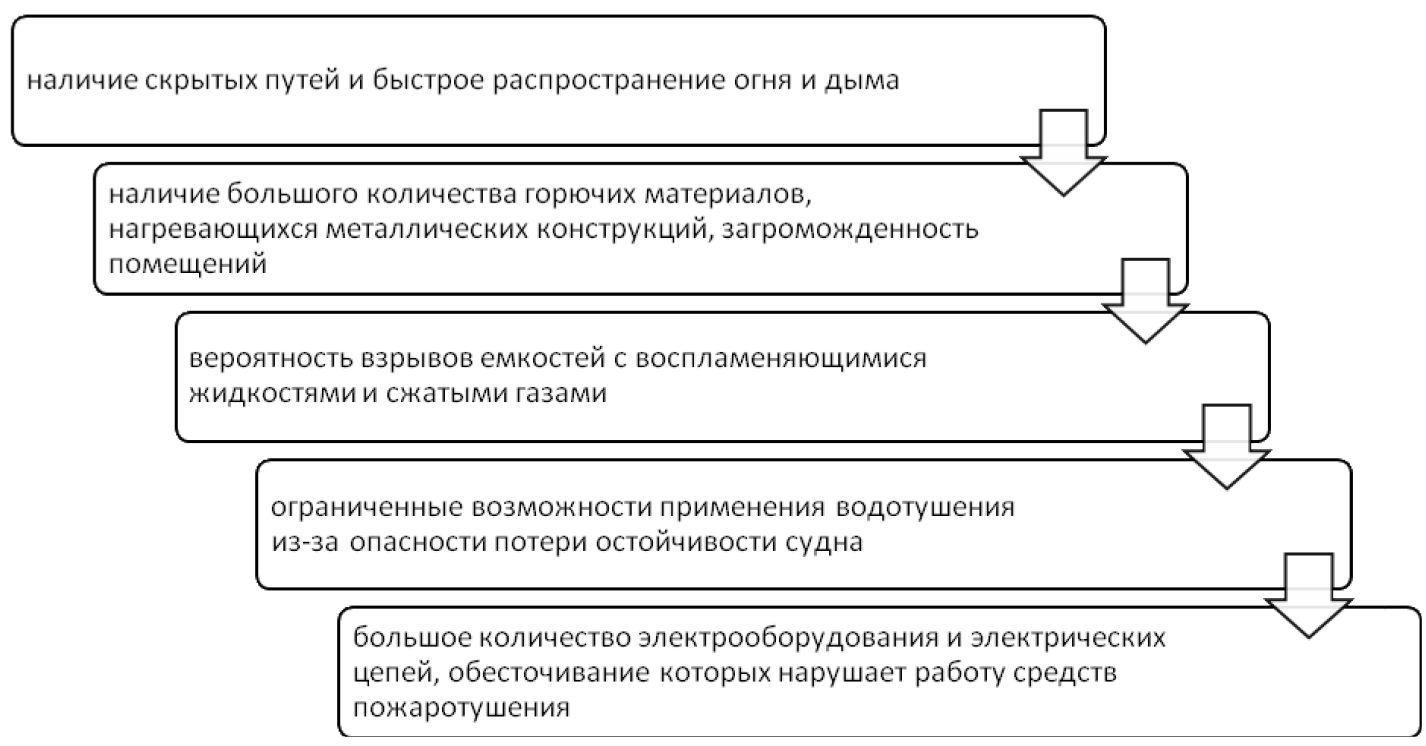

Рис. 1. Факторы быстрого распространению пожара

Основной причиной возникновения возгорания является неосторожное обращение с огнем [3], все другие причины заметно отстают в частоте появления (см. рис. 2).

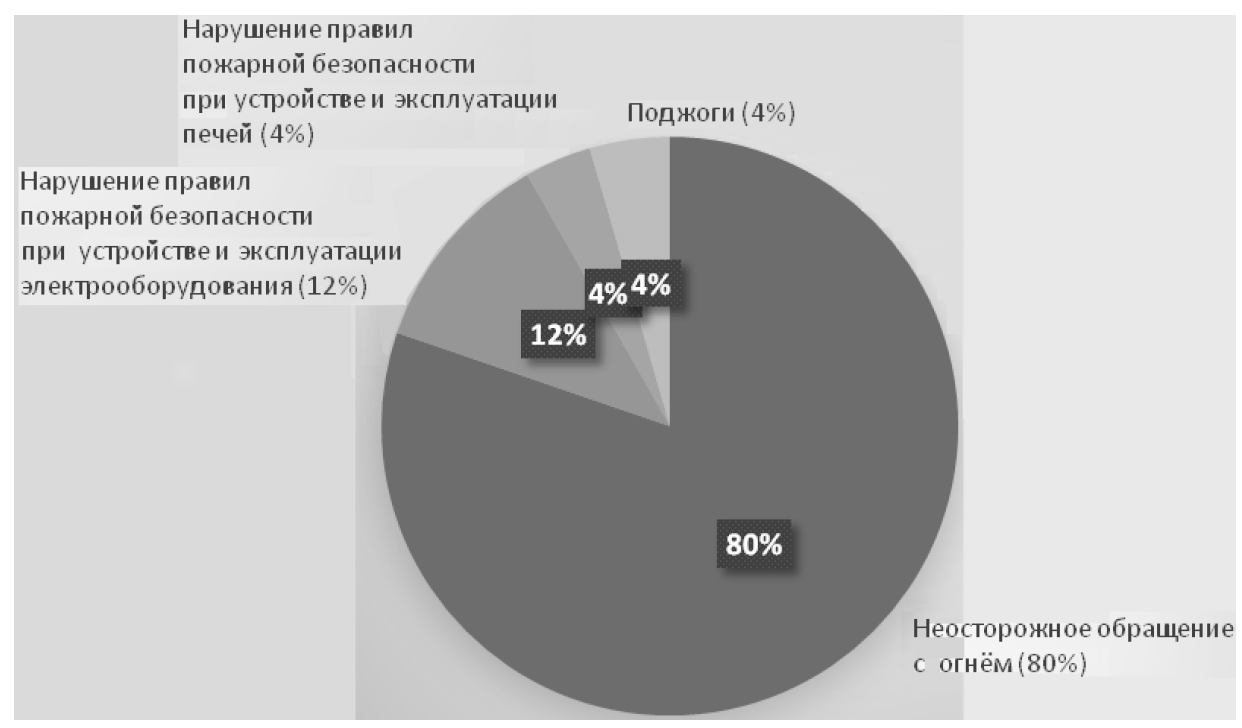

Рис. 2. Основные причины возникновения пожаров 
Для быстрой ликвидации возгорания необходимо знать наиболее подходящие средства для тушения. От этого зависит эффективность борьбы с пожаром и, как результат, уменьшение повреждений судна и сохранение жизни экипажа. Выбор огнетушащих средств зависит от характеристик горючести материалов, находящихся на судне, и от соответствующего класса пожара (см. табл. 3).

Таблица 3

Классификация пожаров

\begin{tabular}{|c|c|c|c|}
\hline Класс А & Класс В & Класс С & Класс D \\
\hline связаны с горением & вызваны & возникают при вос- & связаны с возгор \\
\hline твердых & воспламеняю & пламенении & нием горючих \\
\hline щих золу) горючих & или горючих жидко- & дящегося под & таллов: натрия, ка- \\
\hline материалов, кото- & стей, воспламеняю- & пряжением & лия, магния, титана \\
\hline рые могу & щихся газов, жиров и & оорудов & или алюминия и др. \\
\hline тушены с помощью & других подобных ве- & проводников & тушения \\
\hline воды и в & ществ. Тушение этих & электроус & пользуют \\
\hline творов. К т & пожаров осуществля- & Для пр & глощающие огнету- \\
\hline териалам относятся: & ют прекращением по- & Ния используют ог- & шащие вещества, \\
\hline древесина & ступления кислорода & нетушащие & например, \\
\hline материалы, & К огню или предот- & ва, не являющиеся & порошки, не \\
\hline ткани, & вращением & проводниками & вступающие в реак- \\
\hline $\begin{array}{l}\text { зина и некоторые } \\
\text { пластмассы }\end{array}$ & горю & электричества & $\begin{array}{l}\text { цию с горящими ме- } \\
\text { таллами }\end{array}$ \\
\hline
\end{tabular}

Наиболее часто возникают пожары, совмещающие два класса, и знание классификации может помочь экипажам судов в выборе соответствующего огнетушащего вещества [4].

По требованиям противопожарной безопасности любое судно должно иметь надлежащую конструктивную противопожарную защиту. Помимо деления корпуса водонепроницаемыми переборками на отсеки для обеспечения непотопляемости, судно должно быть разделено на противопожарные отсеки прочными, непроницаемыми переборками с огнестойкой изоляцией и с автоматически перекрывающимися проходами через них. При таком делении судовых помещений в случае возникновения пожара огонь не сможет распространиться по всему судну. Люди без паники в кратчайшие сроки могут быть эвакуированы в безопасную зону и огонь будет быстро ликвидирован при использовании всех средств противопожарной защиты судна, вплоть до применения химических средств тушения огня. Противопожарные конструкции на судах подразделяются на три типа: A, B, C [5].

Количество горючих материалов, применяемых для изготовления внутренних переборок, обрешетников, зашивки, декоративной отделки, мебели и прочего оборудования, постов управления, жилых и хозяйственных помещений (кроме, охлаждаемых) в тех случаях, когда применение таких материалов не запрешается, не должно превышать 45 кг на 1 кв. м площади пола каждого помещения.

Любое возгорание, даже небольшое, требует незамедлительного сигнала тревоги для сбора людей в целях эвакуации. Пробить сигнал пожарной тревоги необходимо таким образом, чтобы было слышно во всех помещениях на судне. При пожаре необходимо обесточить максимально возможное количество электрооборудования, в первую очередь находящееся в проблемной зоне. Для привлечения внимания могут применяться любые средства, например стук, крик, световые сигналы и т. п. Важно обратить внимание на то, что при выводе людей из опасных зон основная часть средств пожаротушения должна находиться на предполагаемых путях эвакуации.

На судне борьбой с пожаром руководит капитан, а при его отсутствии другие уполномоченные лица [6]. Основные действия при борьбе с огнем:

- разведка местоположения возгорания;

- локализация пожара;

- предупреждение взрывов;

- непосредственная ликвидация пожара. 
Разведка позволяет узнать параметры пожара, места возгораний на судне и масштабы происходящего. Разведка заключается в осмотре отсеков, изучении состояния конструкций судна. Параллельно с данным обследованием устанавливают наличие и объем горючих веществ, завалов, особенные условия развития пожара и эвакуационные пути. При обнаружении задымления, членов группы разведки обеспечивают средствами индивидуальной защиты органов дыхания и специальными костюмами. Для доступа к очагу пожарной техники и средств тушения, группа разведки может использовать инструмент для расчистки проходов и разборки конструкции.

С целью предупреждения распространения возгорания необходимо предпринять следующие меры:

- плотно закрыть все проходы и отверстия;

- убедится, что в помещении не остались люди;

- если пожар возник в порту, немедленно сообщить в ближайшую пожарную часть и начальнику порта;

- если пожар возник в море, направить судно к ближайшему порту, берегу или мелкому месту;

- развернуть судно на подветренную сторону;

- уменьшить скорость судна и стабилизировать качку;

- приготовить все опасные грузы к выброске за борт;

- снабдить людей дымовыми масками;

- приготовить к спуску спасательные шлюпки;

- если пожар возник в нижнем трюме, необходимо затопить этот трюм;

- если, несмотря на все принятые меры, не удастся потушить огонь, то, как последнее средство для спасения судна и груза, необходимо затопить судно на мелком месте для того, чтобы поднять его после ликвидации пожара.

Пожарная безопасность судна - одна из важнейших задач обеспечения безопасности судна в целом. Пожар может привести не только к порче имущества, но и к гибели людей, а также к полному затоплению судна вместе с ценным грузом. Поэтому для недопущения возникновения пожара на судне, необходимо:

- соблюдать все требования пожарной безопасности;

- проводить обучение экипажа методам борьбы с пожаром;

- осуществлять профилактику пожаров, контролируя исправность технических средств, целостность переборок и работоспособность систем пожаротушения.

\section{Список литературы}

1. Пожары на судах [Электронный ресурс] - URL: https://flot.com/publications/books/shelf/shipwrecks/ 13.htm.

2. Safety and Shipping Review 2021, AGCS [Электронный ресурс] - URL: https://www.agcs.allianz.com/ content/dam/onemarketing/agcs/agcs/reports/AGCS-Safety-Shipping-Review-2021.pdf.

3. Янченко А.Ю., Горчаков Е.И. Анализ статистики основных причин пожаров на судах различных типов. Неделя науки Санкт-Петербургского государственного морского технического университета. 2019. T. 1. № 1. С. 60.

4. Классификация пожаров на судне [Электронный ресурс] - URL: https://rikisweets.com/klassifikatsiyapozharov-na-sudne/.

5. Конструктивная противопожарная защита судов [Электронный ресурс] - URL: https://mirmarine.net/ poleznaya-informatsiya/bezopasnost-moreplavaniya/1003-konstruktivnaya-protivopozharnaya-zashchitasudov.

6. Ермилов А.В. Способы тушения пожара на морских и речных судах [Электронный ресурс] - URL: https://www.elibrary.ru/download/elibrary_43947737_49472176.pdf.

\section{References}

1. Fires on ships [Electronic resource] - URL: https://flot.com/publications/books/shelf/shipwrecks/13.htm.

2. Safety and Shipping Review 2021, AGCS [Electronic resource] - URL: https://www.agcs.allianz.com/ content/dam/onemarketing/agcs/agcs/reports/AGCS-Safety-Shipping-Review-2021.pdf. 
3. Yanchenko A.Yu., Gorchakov E.I. Analysis of statistics of the main causes of fires on ships of various types / Science Week of St. Petersburg State Maritime Technical University. 2019. Vol. 1. No. 1. P. 60.

4. Classification of fires on a ship [Electronic resource] - URL: https://rikisweets.com/klassifikatsiya-pozharovna-sudne/.

5. Constructive fire protection of ships [Electronic resource] - URL: https://mirmarine.net/poleznayainformatsiya/bezopasnost-moreplavaniya/1003-konstruktivnaya-protivopozharnaya-zashchita-sudov.

6. Ermilov A.V. Methods of extinguishing fire on sea and river vessels [Electronic resource] - URL: https:// www.elibrary.ru/download/elibrary_43947737_49472176.pdf. 